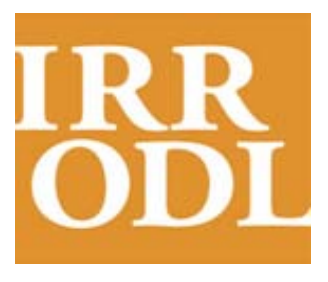

International

Review of

Research in Open

and Distance

Learning

Vol. 12.3

March - 2011

\title{
Emergent Learning and Learning Ecologies in Web 2.0
}

\author{
Roy Williams \\ University of Portsmouth, UK \\ Regina Karousou \\ Independent Educational Researcher, UK
}

Jenny Mackness

Independent Education Consultant, UK

\begin{abstract}
This paper describes emergent learning and situates it within learning networks and systems and the broader learning ecology of Web 2.0. It describes the nature of emergence and emergent learning and the conditions that enable emergent, self-organised learning to occur and to flourish. Specifically, it explores whether emergent learning can be validated and self-correcting and whether it is possible to link or integrate emergent and prescribed learning. It draws on complexity theory, communities of practice, and the notion of connectivism to develop some of the foundations for an analytic framework, for enabling and managing emergent learning and networks in which agents and systems co-evolve. It then examines specific cases of learning to test and further develop the analytic framework.
\end{abstract}

The paper argues that although social networking media increase the potential range and scope for emergent learning exponentially, considerable effort is required to ensure an effective balance between openness and constraint. It is possible to manage the relationship between prescriptive and emergent learning, both of which need to be part of an integrated learning ecology.

Keywords: Emergent learning; prescriptive learning; constraints; retrospective sense-making; learning ecologies; emergent learning networks 


\section{Introduction}

The past decade has seen an exponential increase in the development and use of technologies for interaction and communication across almost all aspects of day-to-day events (at least in the developed world), from learning to work contexts to personal use. The number of blogs, emails, texts, and tweets has gone from zero to numbers in the billions in just a few years. Such innovations have not escaped the attention of higher education, for example, Sharpe, Beetham, and de Freitas (2010) and the related Higher Education Funding Council for England (HEFCE) paper (2009, p.5), which states,

As a result of the pervasiveness of technology, the term 'elearning' has come under scrutiny. Personal ownership of technologies coupled with access to social software means that all kinds of learning-related activity can potentially be e-enabled; e-learning can no longer be viewed as a purely institutionally based or narrowly defined set of activities.... Yet technologyenhanced learning remains a source of concern for institutions...[and] suggests a need to understand better how to design and support learning involving technology. Access, especially to the internet and social software, may have increased, but this does not mean that technology is always used to its best advantage, either by teachers or learners.

Specifically, De Freitas and Conole (2010, p. 29) write that "the main challenge lies in the real transition to a less tutor-led approach to learning...content will not be delivered to learners but coconstructed with them”. This resonates with the notion of emergent learning as learning in which actor and system co-evolve.

The expanded range of teaching and learning possibilities, such as e-books, e-journals, the incorporation of blogs and wikis into standard virtual learning environments (VLEs), Skype, virtual conferencing, and recently Twitter (Malik, 2010), seems to have been welcomed, and many university marketing departments are actively promoting their Web 2.0 profile in the marketplace for student recruitment.

However, their practice is still substantially shaped by traditional teaching modes, prescriptive learning outcomes, normative expectations, and conventional hierarchies. Unless institutions, both in education and at work, broaden their learning spaces to allow greater flexibility and more self-organisation, they might fail to address the possibly growing dilemma that "even when students are in school, much of their education happens outside" (Collins \& Halverson, 2010, p.19).

Most students embrace the digitalised world of social networking (Barnes \& Tynan, 2007), although this does not necessarily transfer to learning. Some students prefer to keep their social networking and their learning quite separate and resent intrusions into their mobile-phone space 
by universities (Conole, de Laat, Dillon, \& Darby, 2006; Sharpe et al., 2010). On the other hand, because the use of mobile phones among students is very high in some countries where computer broadband access may be difficult, such as South Africa, students are increasingly using mobile phones to access learning materials on the Internet (Czerniewicz, Williams, \& Brown, 2009). Both these examples illustrate how students are taking control of their learning with the result that many currently perceived novices are actually becoming silent experts in how, where, and by whom they want to be educated (Alexander, 2003; Schmidt et al., 2009, on the emergence of peer-to-peer interaction). This raises important questions about how institutions and individuals can manage and learn from what these silent experts can bring into the learning community. In addition, graduates living in a learning society are required to demonstrate a much greater level of autonomy and self-organisation than 15 years ago (Antikainen, Kauppila, \& Huotelin, 1996).

In this paper we argue that it might be useful for educational institutions to actively explore alternative frameworks such as connectivism (Siemens, 2005), complexity theory (Cilliers, 2005, 2010), communities of practice (Wenger, 1998, 2006), and the underlying threads of emergent learning to inform their planning and strategy. We will attempt to bring together elements of all these areas of research and practice to develop a framework for emergent learning that can be applied across education, work, and social networking, with their increasingly blurred boundaries. Emergence has been discussed and defined by a number of authors, such as Cilliers (2005), Goldstein (2009) and, at the international systems level, Knorr-Cetina (2005). For the purposes of this paper, we interpret emergent learning as

learning which arises out of the interaction between a number of people and resources, in which the learners organise and determine both the process and to some extent the learning destinations, both of which are unpredictable. The interaction is in many senses self-organised, but it nevertheless requires some constraint and structure. It may include virtual or physical networks, or both.

The debate on networks, connectivism, learner autonomy, and even emergence often has normative overtones as if these things are an end in themselves; the implicit assumption is that if only everyone had the Internet and everyone got connected to everyone else, learning would flourish. See, for instance, Downes (2010a), Siemens (2009), Mitra and Dangwal (2010), and Arora's critique of Mitra, who she says has constructed a "romance that tells of learning free from the chronic obstacles of formal schooling, and children liberated through self-learning" (Arora, 2010, p. 690). See also Mackness, Mak, Fai, and Williams (2010) and Mak, Fai, Williams, and Mackness (2010) for critiques of Downes and Siemens' CCK08 course.

Selwyn (2010) argues the case for a contextual, critical, and social scientific approach to the use of technologies in education. To achieve this, it might be useful to keep in mind that new technologies generally tend to increase discrepancies in power, at least initially, and that, as we argue throughout, connectivity is a necessary but not sufficient condition for learning. It is also important to note that learning that embraces emergence requires us to make decisions about 
values - managing emergence is not an objective enterprise (Cilliers, 2005; Snowden \& Boone, 2007).

\section{Research Approach and Problem Statement}

This is a theoretical paper, drawing on the authors' theoretical and empirical research. The paper explores the theoretical frameworks of complexity, communities of practice, and the notion of connectivism, using qualitative analysis and select cases to try to map out an adequate framework for understanding emergence and its possible use in practice.

The aim of the paper is to describe emergent learning and situate it within learning networks and the broader learning ecology of Web 2.0 and beyond. To do this, we need to explore the following:

- What are the conditions that enable emergent, self-organised learning to occur and to flourish?

- What mechanisms of validation are effective, can emergent learning networks be selfcorrecting, and if so, how?

- Is it possible to link, or even integrate, emergent and prescribed learning, and if so, how?

The distinction between emergent and prescribed learning needs to be unpacked in some detail as it is crucial to the statement of the problem here. Collins and Halverson phrase this slightly differently: They talk instead of "the affordances of digital media" as opposed to "traditional modes of learning," but they share the same concerns, and they stress "the urgency of seeking a [new and] coherent model for the future of education” (2010, p.18).

For the purposes of this paper, we need to be more specific than that, so we draw primarily on complexity theory to map out the distinction between emergent and prescriptive learning (see Figure 1). This provides us with an analytic framework with which to examine the conditions under which emergent learning might occur.

Following Snowden and Boone (2007) and Cilliers (2005, 2010), we can distinguish two different domains of application for learning: the domain of predictable events on the one hand, and on the other hand, the domain of complex-adaptive events, which are not predictable because the agents are self-organising. It is nevertheless possible to make sense, retrospectively, of complex events. 


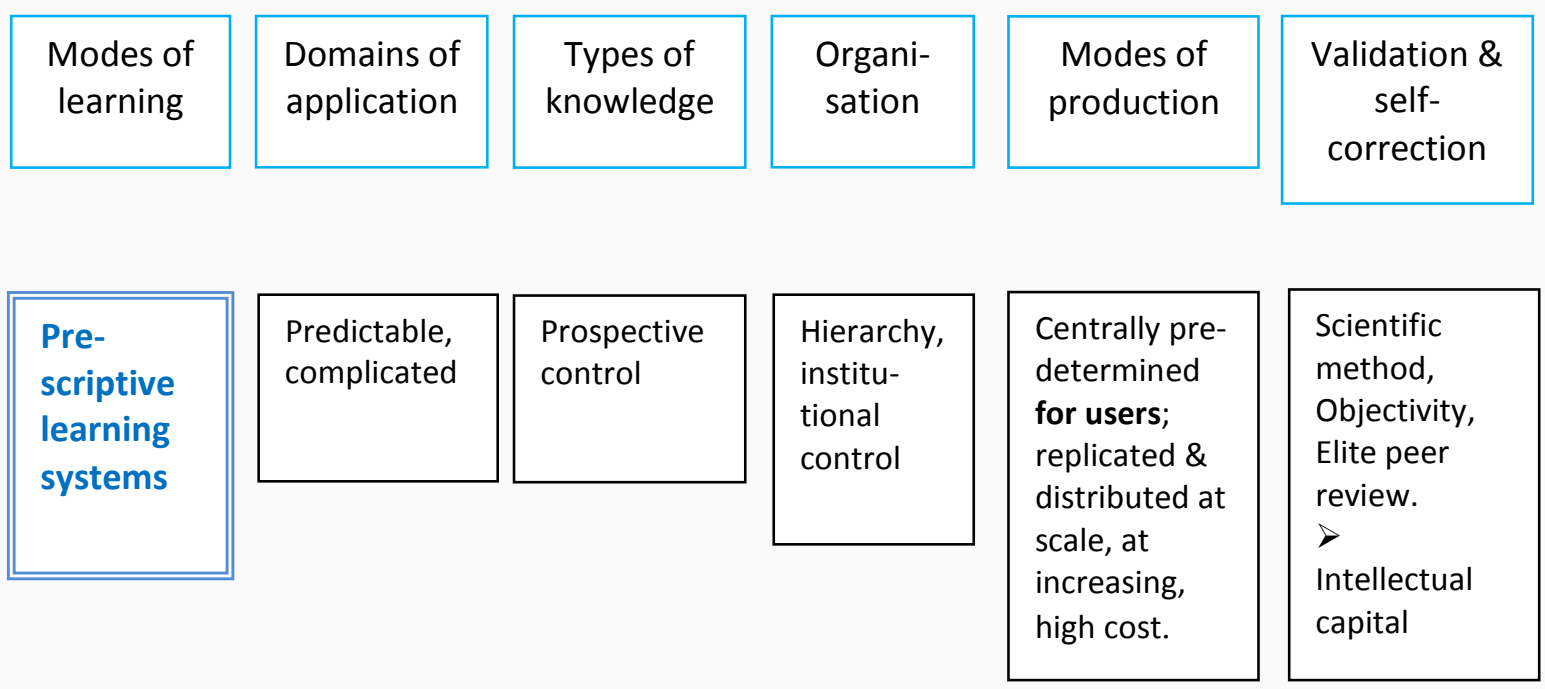

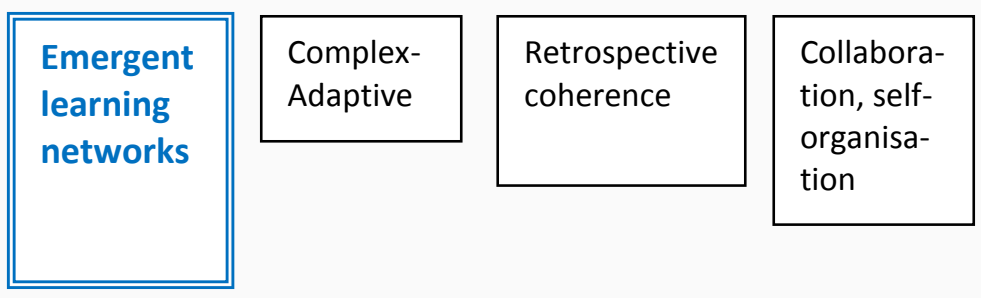

Figure 1. Framework for emergent learning and learning ecologies.

Open \&
distributed.
Created at
scale by
users.
Replicated,
distributed
and reworked
at decreasing,
low cost.

Openness, Interaction scale, constraints values.

$>$ Narratives, Ethnographic accounts.

In predictable domains, knowledge can be created and applied to provide control. The learning that is traditionally associated with predictable domains is typically organised hierarchically within centralised institutions. We will refer to it as prescriptive learning. A better term might be sutured learning, in the Lacanian sense of being sewn up and not negotiable, but for the sake of simplicity, we will stick with the more general term. Prescriptive learning, then, is based on knowledge which is pre-determined for the learners and duplicated and distributed at scale through traditional schools and universities, through print and other mass media, and through national quality-assurance institutions. This covers most formal education in the UK, as well as most traditional publishing and educational broadcasting, and many VLEs.

In complex-adaptive domains, knowledge does not provide prospective predictability but, rather, retrospective coherence: "hindsight does not provide foresight" (Snowden, 2010). The learning that is appropriate is self-organised and typically collaborative. It is open and is created and distributed largely by the learners themselves. Examples include social software communities and networks, some personal learning environments (PLEs), and some communities of practice (CoPs). 
On this basis, we can distinguish between two modes of learning: prescriptive learning systems and emergent learning networks, associated with the two domains of application, predictable and complex-emergent respectively. This is not in itself new. Emergent and prescriptive learning have both always been with us. What has changed is a radical transformation of the modes of production of interaction, communication, and dissemination, collectively referred to as Web 2.0 (see Figure 1), which makes emergent behaviour possible at an unprecedented scale, pace, and breadth of participation. Collins and Halverson (2010) point out that traditional modes of learning arose in response to the industrial revolution and were based on standardised massproduction. The "affordances of digital media," on the other hand, emerged out of the information revolution and the subsequent growth of Web 2.0 social software and "learnerdirected technologies" (Collins \& Halverson, p.18). This poses "direct challenges to how [formal education] operationalizes learning” (p.19). What seems to be emerging now is a third phase, in which the information age is overtaken by the interactive age, in which the emphasis is not so much on the transfer of data by individuals and institutions (in information and communication technology, ICT), but rather on interaction and collaboration within social networking.

(Note: In our framework, the two modes of learning and the two modes of application are presented here as quite separate for analytic clarity, but as soon as prescriptive learning is applied in a social context or explored at the doctoral level, emergent factors also come into play.)

One of the central problems for learning is how to ensure the validation of knowledge and selfcorrection of the system. Validation and self-correction within prescriptive learning systems is based on well-established principles of the scientific method and expert peer review, which successfully produces and disseminates objective intellectual capital. This is not to deny that ethical issues and dilemmas may arise from the application of these "objective” methods, such as in genetic engineering, but the mechanisms for generating and validating knowledge are well established.

This is not the case for emergent learning. The growth and diversity of the modes of production for emergent social networks provide the necessary conditions for an exponential expansion of emergent learning, including openness, interaction, and self-organisation at scale. However, other factors, such as constraints and values, also have to be taken into account. How is it possible, for instance, for the Internet to be used to establish the mistaken consensus of 50 million Americans that Obama is "actually" a Muslim? Where and how did they learn this? (The Times newspaper, UK, $17^{\text {th }}$ September 2010).

Web 2.0 provides the necessary conditions for emergent social behaviour to flourish, but this does not necessarily lead to knowledge or to emergent learning. This is one of the key problems that this paper addresses, but we first need to explore the broader issues of emergence in the next section then return to the specifics of emergent learning. 


\section{Analytic Framework}

Learning can be defined, broadly, as acquiring "knowledge" or the "capacity for effective action" (St Onge \& Armstrong, 2004). It therefore requires individual capacity and a social or institutional context in which to act (Wenger, 2006). Learning has always included both prescriptive learning (which is fixed and predictable) and emergent learning (which is unpredictable and arises out of the interaction between the learners and their context). We will outline the conditions that promote emergent learning, and we will try to show how emergence potentially adds to the affordances for learning but also brings with it requirements for monitoring and rapid response (Snowden \& Boone, 2007).

We need to note that, in terms of complexity theory, emergence can be either positive or negative, depending on the perspective of the person and the social context concerned (Cilliers 2005; Snowden \& Boone, 2007; Snowden, 2010; Rihani, 2002). Emergence may add value to one community but detract from the value of another. Negative emergence may also include rogue or feral individuals or even communities and institutions, such as the derivatives markets in the late “noughties” and Al Qaeda, both of which Knorr-Cetina (2005) shows in detail to be clear examples of emergent networks.

\section{Emergent Learning}

We can now start to add some detail to the framework in Figure 1, specifically for managing emergent learning in a digital, networked world. Siemens describes emergence as

an attribute exhibited by complex systems. The interactions of multiple agents at a local level can create or contribute to significant system-level change.... When applied to learning, we can appeal to emergence as the outcome (understanding?) that arises from different agents interacting and producing unanticipated outcomes. (2009)

Since emergent learning is unpredictable but retrospectively coherent, we cannot determine in advance what will happen, but we can make sense of it after the event. It's not disordered; the order is just not predictable. We can summarize this as follows: Emergent learning is likely to occur when many self-organising agents interact frequently and openly, with considerable degrees of freedom, but within specific constraints; no individual can see the whole picture; agents and system co-evolve.

Why is it important? Emergent learning is open and flexible, so it is responsive to context and can adapt rapidly, particularly in a world in which careers, professions, identities, competencies, and roles, as well as interactive and communicative media, are rapidly changing. However, openness needs to be counterbalanced by constraint and inclusive values. If all these factors are present, emergent learning is possible, and even probable. If not, however, emergence can 
degenerate into isolated virtual ghettoes, or "echo chambers" (self-perpetuating and selfreinforcing enclaves), which may reinforce prejudice rather than produce the "wisdom of the crowd” (Alakeson, Aldrich, Goodman, Jorgenson, \& Miller, 2003).

Emergence is not a panacea, it is an option, and we will argue that it has to be situated within and preferably integrated within - an overall, inclusive learning ecology, along with prescriptive learning as and where appropriate.

\section{Managing Emergence}

Snowden and Boone (2007), Snowden (2010), and Cilliers (2005, 2010) provide detailed analyses of the necessary conditions for managing emergent learning. Snowden contrasts two approaches to management: "safe/fail experiments" as opposed to "fail-safe management," in emergent or "complex" domains and in predictable or "ordered" domains, respectively. Fail-safe management aims at ensuring compliance with predictable outcomes, whereas safe/fail experiments aim at encouraging interaction and self-organisation and enabling emergence and innovation, which is managed by

- a heightened awareness of changes in attractors, boundaries, and emergence;

- a system of negative constraints which determine what is not allowed to happen, rather than specifying what does have to happen;

- continuous monitoring, response, and recovery, good weak-signal detection of "outlier" events, light-touch response where possible, and quick and decisive intervention where necessary, including dampening negative emergence and accentuating positive emergence;

- an emphasis on resilience, (i.e., allowing mistakes but rapidly responding and recovering), rather than on robustness, which does not allow for mistakes or for learning from mistakes;

- creatively using retrospective coherence rather than trying to force compliance and predictability where it might not be appropriate or even possible, particularly in performance targets.

\section{Designing for Emergence?}

Wenger (1998, p. 267) writes that designing for emergence can only be an intention; learning will be emergent whether it is designed for or not; we cannot anticipate what will emerge. The design process should be interpreted more as an attitude, a set of principles, or a philosophical approach than a practice. The details of the design are not the issue - it is the interaction between the planned and the emergent that matters. This involves an iterative feedback/feed-forward loop, where one is continually affecting the other and adjusting accordingly. This suggests that the planning and design should be as emergent as the learning. 


\section{Structure and Constraint}

Cilliers (2005) specifies the dynamics between structure and complexity in some detail:

The structure of a complex system enables it to behave in complex ways. If there is too little structure, i.e., many degrees of freedom, the system can behave more randomly, but not more functionally. The mere 'capacity' of the system (i.e., the total amount of degrees of freedom available if the system was not structured in any way) does not serve as a meaningful indicator of the complexity of the system. Complex behaviour is possible when the behaviour of the system is constrained. On the other hand, a fully constrained system has no capacity for complex behaviour either. (p.258)

In other words, both openness and constraints must be continuously monitored, managed, and balanced.

\section{Knowledge Ecologies}

Prescriptive and emergent learning have always occurred in education, work, and informal settings in some measure. The differences lie in the balances between prescriptive and emergent learning, the degree of formalisation of learning, and the different levels of resources which each sector applies to them.

Learners have always been self-organised to some extent, even if this was on the borders of institutional practices. What has changed is that learners not only have access to the affordances of individualised tools to construct personal learning environments (PLEs), but that these are increasingly embedded in social networks which are, in turn, emergent and self-organising. These PLEs might therefore better be seen as "personal learning ecologies" or "personal ecological niches or nodes." Knorr-Cetina writes that many emergent practices "simply outrun the capacity of [prescriptive, Weberian] structures. Global systems based on micro-structural principles do not exhibit institutional [structures]...but rather the asymmetries, unpredictabilities, and playfulness of complex (and dispersed) interaction patterns” (2005, p.214).

In principle and in practice, we are rapidly moving into much broader knowledge ecologies (Peters, 2009) which link many sites of learning and networks that include both prescriptive and emergent elements. We need a new language to describe and analyse the way in which emergent learning occurs in different settings or how structure and agency co-evolve in complex systems (Snowden, 2010).

The interactive potential of Web 2.0 provides unprecedented opportunities and affordances for emergent learning. However, enabling, resourcing, and managing a learning ecology which 
integrates prescriptive and emergent learning requires people who can work across these two very different systems that are based on quite different epistemologies.

\section{Applying the Framework}

A number of issues or themes will be explored to flesh out the analytic framework in more detail and test it against practice and research. Various theories, particularly complexity, affordances, and communities of practice, as well as the concept of connectivism, will be drawn upon to analyse these cases to try to provide a better understanding of how we can enable and manage emergence in a digital, networked world.

\section{Validation and Self-Correction}

Validation and self-correction within emergent learning networks remains an issue. Many academics still dismiss emergent learning and Web 2.0 as peripheral or even irrelevant to "real" formal learning because they see no mechanisms for validation and self-correction. Wikipedia provides a good example of emergent learning, based on micro-agents interacting at scale. The point is that Wikipedia is an emergent learning network, not a prescriptive learning system, and it would be a mistake to try to judge Wikipedia by any other criteria. It's a paradigm case of what may be called open source content, with mechanisms for validation and self-correction based on frequent interaction by micro-agents in an open system with negative constraints. It turns the commissioning structure of conventional encyclopaedias on its head.

\section{Beyond Prescriptive Learning}

In research conducted for the UK Higher Education Academy's Learning Observatory programme, learning narratives were gathered to explore how students actually went about their learning (Williams, Karousou, \& Gumtau, 2008). One of these narratives, Learning Journey, illustrates the way in which emergent learning may arise serendipitously, as it were, in the learning of someone enrolled for a prescriptive learning programme.

This narrative concerns the learning that takes place when April, a mature part-time student in an Early Years Childhood Education degree, goes on a visit to a preschool centre of excellence and a related preschool. April is a preschool manager. On her visit to the centre, she notices:

There were certain things that stuck in my mind about their environment that was completely different to my own. For instance, they have glass bottles, glass vases with flowers on the tables. And really, the fact that the children were so well behaved and quiet, made a big impression, thinking: how can I influence my children to be quieter? 
April engages with several staff members at the school and the centre and becomes a member of an informal community of practice $(\mathrm{CoP})$. From her interaction within this $\mathrm{CoP}$, she gains enough confidence to embark on a complete change management programme at her own preschool (despite the skepticism of her fellow teachers), incorporating ideas from her visit and from further interaction in this CoP.

April was only required to write up a report on her visit and some lessons learnt. However, her learning journey goes way beyond the requirements of her prescriptive learning programme, particularly at a first-year level, in what might be called emergent learning. April engages in an unpredicted and far more complex task than was prescribed by her course. This learning was retrospectively coherent and influenced by her participation in an implicit and emergent community of practice. Although this community was small and several participants could probably "see the whole picture," April's learning within it was not formally managed. April's case is one of entirely self-organised, small-scale emergent learning with little or no integration into formal, prescriptive learning or the curriculum.

\section{Assessment}

Amplifying, celebrating, and recognising this emergent learning was unlikely within the context of April's course. Romer argues that "the traditional interpretation [of assessment] becomes problematic because an assessment of [such a] student according to the principles of [the course]...will be incapable of capturing the student's creativity” (2002, p. 238-239). Examples like this, which are becoming increasingly frequent as more mature students are invited back into higher education as part of the "widening participation" programme in the UK, reflect the need for finding a workable way to integrate and move between the plurality of various communities, the multiple and disjointed individual trajectories, and the possibilities for amplifying, rather than just ignoring, emergent learning like this. The question is whether it is possible to bring such emergence back into a closed learning system and the institution's assessment framework.

\section{Dampening and Amplifying Emergence}

As we have said, emergence allows new affordances, but these may be positive or negative. There are many uses of the term affordances, so it might be useful to define the particular sense in which we use it in this paper more precisely, before we continue:

An Affordance is the product of interactions between a person and their environment, each of which potentially alters their knowledge, competencies and identity, and potentially alters the (micro-) environment...[and]...Learning is the process of exploring, benchmarking and mastering new affordances. (Williams et al., 2008)

Re-defining learning in terms of affordances in this way enables us to account for both prescriptive and emergent learning within an inclusive learning ecology, and it allows us to link 
learner, identity, and context, as in Wenger's concept of social learning (2006). This notion of affordances allows for potentially large adaptations by both learner and environment, but does not require it. In general terms, one would expect a lot of mutual adaptation in emergent learning (by definition). In prescriptive learning, on the other hand, one would expect much less adaptation on the part of the learner and possibly none at all on the part of the (virtual or otherwise) learning environment.

A learning programme that requires students to explore a particular field, but in a way that encourages emergence, still has to be managed, albeit differently from the way learning is traditionally managed (see Snowden \& Boone, 2007). Most important of all, negative constraints must be put in place and communicated to the participants. Secondly, the instructors or facilitators must dampen negative emergence and amplify positive emergence.

The case that most clearly illustrates some of these issues is the University of Manitoba's massive open online course, CCK08, on Connectivism, designed by Downes and Siemens, which ran between September and December 2008 (Downes, 2009). CCK08 was based on the connectivist principles of connectivity, openness, diversity, and autonomy.

The course content was available from the start on the course wiki, and participants were free to plan their own paths through this content, engaging at their own levels in media of their choice. Implicit in the course design was the expectation that information and expertise would be freely shared and knowledge would be created collaboratively. Connectedness and interactivity lay at the heart of the course design. It was expected that knowledge would be emergent in the network and become a resource for the network as a whole.

The course also provided an innovative "blog-aggregator," in which participants' blogs (and some forum discussions) were scanned on a daily basis, and leads and links to these postings were aggregated and captured in a daily electronic newsletter. This is an excellent example of how emergence can be harvested, enabled, and amplified by putting into practice "weak-signal detection of 'outlier' events [blogs]," and communicating them to the whole network (see the Managing Emergence section).

The course was designed to be completely open and self-registering. This was in many ways a radical experiment, which satisfied some of the key conditions for emergent learning: "the interactions of multiple agents at a local level [which] can create or contribute to significant system-level change...different agents interacting and producing unanticipated outcomes” (Siemens, 2009).

However, it did not, in practice, achieve a balance between constraint and degrees of freedom. The tolerance and lack of guidance on what to do about the very disruptive troll behaviour from one participant in the first part of the course (who disrupted the work of course participants through aggressive behaviour), and the total imposition of the "power demonstration" exercise near the end of the course, used too little and too much constraint respectively, and participation and emergent learning were compromised. Wikipedia [2010] defines a troll as 
someone who posts inflammatory, extraneous, or off-topic messages in an online community, such as an online discussion forum, chat room, or blog, with the primary intent of provoking other users into a desired emotional response or of otherwise disrupting normal on-topic discussion.

One of the established ways of dealing with troll behaviour is the 'do not feed the troll' (DNFTT) protocol (i.e., all participants ignore the troll's contributions), but this was not used in CCK08.

The majority of the respondents in the Mackness et al. research (2010) on CCK08 showed that they left the forums, some probably left the course, and many became bloggers exclusively because they were "refugees from the forums," who wished to escape from an environment in which there were no apparent constraints.

So connectedness per se does not ensure interaction, let alone emergent learning. As Siemens said, some months later, “The question for me is not 'how are people connected?' but rather 'what are the implications of people being connected in a certain way?'....Frequency of contact isn't that important to me” (2009b).

The challenge is to map out carefully, in detail, the most appropriate way for people to be connected and to ask the question, can and should a course based on self-organisation also be self-managed, or is there a crucial distinction to be made between self-organisation and selfmanagement in practice?

\section{Emergent Curriculum}

Courses can also be deliberately designed as adaptive systems, in which learning emerges. The MA in Management Learning and Leadership Programme (MAMLL) course at Lancaster University in the UK is an example in which the curriculum itself is emergent, although still within the quality assurance framework for master's courses (this might have been more difficult in an undergraduate course).

MAMLL subscribes to a belief in an open syllabus and self-managed learning. The curriculum is seen not as a description of content but as the product of the interaction between people who are active in the domain and negotiating workshops and assignments, people who will produce resources for future students.

We believe that individuals often know what they need to become more effective, and have a keen sense of their own priorities and interests. This is why we work with an 'open syllabus', where the content of the workshops, and the literature drawn upon, is shaped by both tutors and participants. 
In this sense, the course is an adaptive system which is not restricted to a pre-determined representation of a student or domain, but allows students to be creative and engage in their own acts of representation (as advocated by Downes, 2010a). This negotiated curriculum means that no two programmes ever look quite the same. The programme is a dynamic network for learning, continuously shaped and re-shaped by its members. The outcomes can therefore be unpredictable and surprising. The course thus satisfies the overall criterion for emergent learning: "a learning ecology in which agents and system co-evolve” (Lancaster University).

The course has been running for 27 years as a part-time programme. It takes a social constructionist approach to learning and has adopted and adapted some of the principles of the theories of communities of practice and networked learning to encourage learners to take control over their own learning and follow their own lines of enquiry (Hodgson \& McConnell, 1992). In this sense, the course design promotes emergent learning. The programme also promotes diversity by recruiting mature learners from all around the world and from all employment sectors. It provides a forum for face-to-face and online networking amongst participants, academics, researchers, practitioners, and alumni, thus enabling connections between people, ideas, and online and other resources (Hodgson \& Zenios, 2003). In terms of emergence, this emphasis is the specific factor of diversity, a factor which was also foregrounded in connectivism in CCK08 (Downes, 2010a).

Whilst the programme is informed by social learning theory (Wenger, 1998, 2006), the emphasis has been on developing a network of learners rather than a community of practice because the course leaders believe that CoPs have the potential to be oppressive, exerting pressure towards conformity and crushing individual autonomy (Ferreday \& Hodgson, 2008). Specifically, the course leaders believe that resistance to the core values of the community and its norms of behaviour, or difference in terms of gender, role, age, and so on can result in marginalisation and isolation, and that some students may not feel represented by the terms or expectations of a community. The MAMLL course supports the recognition and maintenance of difference and allows "defiant speech" and "talking back." Differences and ambiguity are accepted without an expectation that they should somehow be resolved (Hodgson \& Reynolds, 2005). This subtle difference from a community-of-practice approach is, in practice, positively significant for emergent learning, which is ensured by the existence of specific, limited constraints.

Although the course emphasis is collaborative assessment, peer feedback, and students' contributions to the marking process, it is acknowledged that the power of assessment remains invested in the tutors and institution and that there are hierarchical differences between students and tutors. Whilst tutors recognise that academics are not necessarily authorities in a course where students can negotiate their curriculum and that they can learn a lot from the negotiated curriculum and students, the course is not a free-for-all and tutors do not abdicate responsibility for their students' learning.

[W]e recognise that this process needs to be facilitated to be most effective. Tutors add new perspectives to the ideas participants already have, by sharing thoughts, concepts, models, 
etc, from their own research and practice, their academic interests and the literature. (see http://www.lums.lancs.ac.uk/masters/mamll/aims/)

Emergent learning is therefore enabled in the MAMLL course by a fine balance between networks and communities of practice, to some extent constrained by the practices and regulations of the traditional education system.

\section{Self-Organised Enquiry-Based Learning?}

The CCK08 course was an experiment in emergent learning, based on the radically different affordances of Web 2.0. So too is Mitra's Hole in the Wall (HiW) project, in which he tries to address the chronic failure that "rural India has been plagued with...in delivering quality education” (Arora, 2010, p.689). He has built up a body of experiments to attempt to address this, starting with

a computer...embedded in a wall of a slum area of Kalkaji, New Delhi, to see what use the local children would make of it without instruction or guidance. A touchpad was built into the wall...and a video camera placed on a nearby tree to record the children's activity. (p. 690)

Mitra's research shows that many of the children achieved substantial learning on their own. This learning was clearly not prescribed but emergent. However, in some cases a lack of monitoring and intervention caused the experiments to fail. Arora (2010) applauds Mitra's work but also documents some of the failures that she encountered in her research on HiW projects in two communities in the Himalayas: in Almora, due to vandalism, and in Hawalbagh, due to lack of finance and monitoring and support. In the light of these findings, Mitra has now added facilitators, either locally or, most innovatively, by employing grandmothers, connected to learners via Skype-Internet phone calls, in what he calls the "granny cloud." The facilitators are not subject experts; their main role is to encourage and support the children's own learning. Arora and Mitra have both recognised that for emergent learning to be effectively managed, it needs to be balanced with appropriate intervention and constraints. (Mitra \& Dangwal, 2010; Mitra \& Arora, 2010).

In one sense it is not remarkable that the children learn to use computers as they learn to use mobile phones without any training. What is remarkable is how much they can learn, with how little guidance, if their self-motivation and self-organisation is encouraged and enabled. For Mitra and Dingwall (2010), the question is, can that self-motivation be sustained and not veer off into computer games, as happened in some cases?

Mitra has now set up a company (HiWEL), which is working with schools, but he is determined to maintain effective self-organised learning because "the absence of a teacher can sometimes encourage children to explore more bravely than they would in their presence” (Mitra \& Arora, 
2010). This is, if anything, a more risky project as reforming schools is notoriously difficult, particularly if you want to convince them of the value of the "absence of teachers." As Arora points out, "the conundrum HiWEL has to face is that it has to strategically engage with schools to justify its presence due to the absence of instruction" because it could be seen to imply that "teachers should stay away to encourage children towards free learning” (2010, p. 696).

Mitra has built up a meticulous body of research to show maintained and even increased retention of knowledge by many of the children following his minimal interventionist approach. But as Arora points out, there is an inherent clash of cultures, of institutional discourses, between rural teaching "embedded in rote learning” and "knowledge discovery and knowledge creation," or emergent learning (2010, p. 696). Mitra's current definition of emergence - "emergence occurs when a system starts to do things that it was never designed for" - may confuse and unsettle teachers even more (Mitra, 2010). There is no doubt that Mitra's project is breaking new ground in at least three quite distinct areas: self-organised learning, cloud-based facilitation, and rural education. The strategic questions about how to find a point of engagement for this emergent learning with the Indian education system, however, seems to have a long way to go.

\section{Conclusion}

In this paper, we have described the unprecedented affordances that Web 2.0 offers for interaction and communication and for emergent learning, as well as some of the substantial challenges in realising this potential in education. We have mapped out the characteristics of emergent learning and situated it within learning as a whole, distinguishing it from more traditional modes of learning in order to provide the basis for integrating both of these two modes of learning within an overall learning ecology. To do this, we have drawn on complexity theory, communities of practice, and connectivism and analysed cases that illustrate some of the key issues. In the process, we hope to have provided some foundations for a framework for emergent learning as well as for a more inclusive, flexible, and adaptable learning ecology.

Such a framework would be based first on the technical or infrastructural conditions for emergent learning. ICT is fast morphing into the social software of Web 2.0 and the augmented reality of cloud-based Web 3.0. ICT has changed beyond recognition, providing global open access at extremely low cost, for not only consuming, producing, and distributing texts and artefacts but for interaction, communication, and networking.

Secondly, emergence requires new institutional and social memes and structures. Some innovative legal frameworks which are already in place provide clear protocols and resources for collaboration and sharing, notably Open Source licences for collaborative software and Creative Commons licences for collaborative and shared content. Many free (mostly advertising-driven) platforms are also in place, from Google to a range of social software and cloud-based "apps" downloadable applications.

And thirdly, there is a need for a shift from a monolithic learning environment in which everything must be controlled and predictable to a more pluralistic learning ecology in which 
both prescriptive and emergent application domains and modes of learning have their place, and in which it is possible to celebrate the unpredictable. This requires quite a different mindset, in which there is a role for safe/fail as well as fail-safe management, a role for resilience as well as robustness, and a balance between pro-spective and retro-spective sense-making of teaching and learning (see section on Managing Emergence).

Institutional change is also at issue. The debate between Mitra and Arora highlights the difficulties in convincing teachers to change. Curriculum change, and particularly radical curriculum change, is difficult, precisely because it challenges embedded practices - embedded pedagogically, culturally, and socially. The question for proponents of emergent learning and Web 2.0 is whether this just "triggers a romance which tells of learning free from the restrictions of formal schooling and children liberated through self-learning” (Arora, 2010, p. 690) or whether a new two-state learning ecology can be achieved, in theory and in practise.

The degree to which the learning can usefully be based on self-motivation and self-organisation depends on three things: the quality of the interaction afforded by the resource and the facilitator, the range of affordances for open interaction with other peers (or micro-agents), and the moderation of the balance between openness and constraints. This is true whether the learning takes place in a Hole-in-the-Wall kiosk linked to a granny cloud, an open learning network, or within moderated peer learning in an online course in higher education.

There are a number of approaches to learning that are premised on a mix of self-interest, internal motivation, self-organisation, and peer-interaction, from Montessori classrooms to enquiry- and problem-based learning, to negotiated curricula and a range of online and open learning programmes. It is fairly obvious that any learning model, and particularly enquiry-based ones, would benefit from more interaction and access to information. The point about what Mitra (2010) initially called minimally invasive education and is now calling self-organised learning environments (SOLEs) is not that emergent learning networks should replace or displace prescriptive learning or teachers or that enquiry benefits from access to better resources, but rather that space needs to be made for substantial, self-motivated, self-organised, emergent learning, per se. This should be recognised as a vital - not a peripheral - part of a learning ecology that includes both emergent and prescriptive learning in a world in which Web 2.0 platforms offer unprecedented affordances for information, interaction, networking, and collaboration, as well as for unique challenges. 


\section{References}

Alakeson, V., Aldrich, T., Goodman, J., Jorgenson, B., \& Miller, P. (2003). Social responsibility in the information society. Digital Europe final report. Retrieved from https://www.forumforthefuture.org/files/DigitaleuropeSocialresponsibilityintheinformatio $\underline{\text { nsociety.pdf }}$

Alexander, P. A. (2003). The development of expertise: The journey from acclimation to proficiency. Educational Researcher, 32(8), 10-14. Retrieved from http://edr.sagepub.com/content/32/8/10.full.pdf+html

Antikainen, A., Kauppila, J., \& Huotelin, H. (1996). Living in a learning society: Life histories, identities and education. London: Falmer Press.

Arora, P. (2010). Hope-in-the-wall? A digital promise for free learning. British Journal of Educational Technology, 41(5), 689-702.

Barnes, C., \& Tynan, B. (2007). The adventures of Miranda in the brave new world: Learning in a Web 2.0 millennium. ALT-J, Research in Learning Technology, 15(3), 189-200.

Cilliers, P. (2005). Complexity, deconstruction and relativism. Theory, Culture and Society, 22(5), 255-267.

Cilliers, P. (2010). The value of complexity. A response to Elizabeth Mowat \& Brent Davis. Complicity: An International Journal of Complexity and Education, 7(1), 39-42.

Collins A., \& Halverson R. (2010). The second educational revolution: Rethinking education in the age of technology. Journal of Computer Assisted Learning, 26, 18-27.

Conole, G., de Laat, M., Dillon, T., \& Darby, J. (2006). JISC LXP Student experience of technologies. Final Report. JISC. Retrieved from http://www.jisc.ac.uk.

Czerniewicz, L., Williams, K., \& Brown, C. (2009). Students make a plan: Understanding student agency in constraining conditions. ALT Journal, 17(2), 75-88.

De Freitas, S., \& Conole, G. (2010) The influence of pervasive and integrative tools on learners' experiences and expectation of study. In Sharpe, R. et al. (Eds.), Rethinking learning for a digital age (pp. 15-30). London: Routledge.

Downes, S. (2009). Access 20ER: The CCK08 solution. Retrieved from http://halfanhour.blogspot.com/2009/02/access2oer-cck08-solution.html 
Downes, S. (2010a). The representative student. Presentation delivered to Technology Enhanced Knowledge Research Institute (TEKRI) at Athabasca University, Edmonton, Alberta. Retrieved from http://www.downes.ca/presentation/257

Downes, S. (2010b). Some questions. Retrieved from http://halfanhour.blogspot.com/2010/06/series-of-questions.html

Ferreday, D., \& Hodgson, V. (2008). The tyranny of participation and collaboration in networked learning. Proceedings of the 6th International Conference on Networked Learning 2008. Retrieved from http://www.networkedlearningconference.org.uk/past/nlc2008/abstracts/PDFs/Hodgson_ 640-647.pdf

Goldstein, J.A. (2009). The status of emergence. Journal of Philosophy, 39(18), 486-93.

HEFCE. (2009). Effective practice in a digital age. Retrieved from http://www.jisc.ac.uk/media/documents/programmes/elearningpedagogy/effectivepractic edigitalage textonly.doc

Hildreth, P.M., \& Kimble, C. (2002). The duality of knowledge. Information Research, 8(1). Retrieved from http://informationr.net/ir/8-1/paper142.html

Hodgson, V., \& McConnell, D. (1992). IT-based open learning: A case study in management learning. Journal of Computer Assisted Learning, 8, 136-150.

Hodgson, V., \& Zenios, M. (2003). Designing networked environments to support dialogical learning. CSCL Conference.

Hodgson, V., \& Reynolds, M. (2005). Consensus, difference and 'multiple communities' in networked learning. Studies in Higher Education, 30(1), 11-24.

Knorr-Cetina, K. (2005). Complex global microstructures. Theory, Culture and Society, 22(5), 213-234.

Mackness, J., Mak, Sui, Fai, J., \& Williams, R. (2010). The ideals and reality of participating in a MOOC. In Networked Learning Conference (pp. 266-274). Retrieved from http://www.lancs.ac.uk/fss/organisations/netlc/past/nlc2010/abstracts/Mackness.html

Mak, Sui, Fai, J., Williams, R. \& Mackness, J. (2010). Blogs and forums as communication and learning tools in a MOOC. In Networked Learning Conference (275-284). Retrieved from http://www.lancs.ac.uk/fss/organisations/netlc/past/nlc2010/abstracts/Mak.html

Malik, M. (2010). Two year case study: Technology assisted project supervision (TAPaS). Engineering Education (Loughborough), 4(2), 76-82. 
Mitra, S., \& Dangwal, R. (2010). Limits to self-organising systems of learning - The Kalikuppam experiment. British Journal of Educational Technology, 41(5), 672-688.

Mitra, S., \& Arora, P. (2010). Afterthoughts. British Journal of Educational Technology, 41(5), 703-705.

Mitra, S. (2010). The child-driven education. TED presentation. Retrieved from http://www.ted.com/talks/lang/eng/sugata_mitra_the_child_driven_education.html

Peters, M.A. (2009). Open education and the open science economy. Yearbook of the National Society for the Study of Education, 108(2), 203-225.

Rømer,T. A. (2002). Situated learning and assessment. Assessment and Evaluation in Higher Education, 27(3), 233-241.

Rihani, S. (2002). Complex systems theory and development practice: Understanding non-linear realities. London: Zed Books.

Schmidt, J. P., Geith, C., Håklev, S., \& Thierstein, J. (2009). Peer-to-peer recognition of learning in open education. International Review of Research in Open and Distance Learning, 10(5). Retrieved from http://www.irrodl.org/index.php/irrodl/article/view/641/1392

Selwyn, N. (2010). Looking beyond learning: Notes towards the critical study of educational technology, Journal of Computer Assisted Learning, 26(1), 65-73.

Sharpe, R., Beetham, H., \& de Freitas, S. (Eds.). (2010). Rethinking learning for a digital age: How learners are shaping their own experiences. London: Routledge.

Siemens, G., \& Cormier, D. (2010). Peer assessment. Online course on futures in education. Retrieved from http://edfutures.com/blogs/davecormier/accreditation-and-assessmentopen-course-opening-proposal

Siemens, G. (2009). Complexity, chaos, and emergence. Retrieved from http://docs.google.com/View?docid=anw8wkk6fjc 15cfmrctf8

Siemens, G. (2009b). Different social networks. Retrieved from http://www.elearnspace.org/blog/2009/07/30/different-social-networks/\#respond

Siemens, G. (2005). Connectivism: A learning theory for a digital age. Retrieved from http://www.elearnspace.org/Articles/connectivism.htm

Snowden, D.J. (2010, June). Complexity. Online webinar to the Critical Literacies Open Course. Retrieved from http://www.downes.ca/cgi-bin/page.cgi?post=52307 
Snowden, D.J., \& Boone, M. (2007). A leader's framework for decision making. Harvard Business Review.

St Onge, H., \& Armstrong, C. (2004). The conductive organisation. Oxford: Elsevier.

Wenger, E., White, N., \& Smith, J. (2009). Digital habitats. Stewarding technology for communities. CPsquare.

Wenger, E. (2006). Learning for a small planet (Project proposal). Retrieved from http://www.ewenger.com/research/

Wenger, E. (1998). Communities of practice. Meaning, learning and identity. USA: Cambridge University Press.

Wikipedia. (2010). Trolls. Retrieved from http:///en.wikipedia.org/wiki/Troll_\%28Internet\%29

Williams, R.T., Karousou, R., \& Gumtau, S. (2008). Affordances for learning and research (Final project report for the Higher Education Academy). Retrieved from http://learningaffordances.wikispaces.com/Project+Report

\section{Athabasca University $\mathbf{A}$}

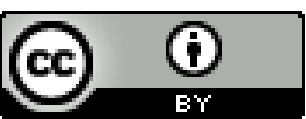

